\title{
THERMAL ANALYSIS ON FRICTION STIR WELDED ALUMINUM PLATES
}

\author{
SAROJ KUMAR PADHI ${ }^{1}$, MANI KUMAR ${ }^{2}$, MUGHAL SRIKANTH ${ }^{3}$, \\ SRI KRISHNA SAI ADITYA ${ }^{4} \&$ RAHUL $^{5}$ \\ ${ }^{I}$ Associate professor, Department of Mechanical Engineering, Koneru Lakshmaiah Education Foundation, \\ Vaddeswaram, Guntur, Andhra Pradesh, India \\ ${ }^{2,3,4,5}$ UG Scholar, Department of Mechanical Engineering, Koneru Lakshmaiah Educational Foundation, \\ Vaddeswaram, Guntur, Andhra Pradesh, India
}

\begin{abstract}
In order keeping in mind with the high advanced strength of aluminum alloys, some automotive manufacturers are looking forward to being introduced high strength Al-alloys like AA7075, AA6061, AA6068 etc. that have optimum mechanical properties. The joining of these Al-alloys by fusion weldings like regular weldings such as arc welding and tungsten inert gas welding will not lead to better mechanical properties. In the last decade, friction stir welding, one of the best-advanced welding combinations are employed for Al-alloys as it improves mechanical properties and overcomes constraints of the ordinary welding processes. FSW is plasticized state joining technique in which is no melting is involved and it also energy proficient and free from consumables and radiation. It can produce acceptable quality joints. The standard and strength of the joints which can be estimated and calculated in terms of the improved mechanical properties like yield strength, hardness, bending strength, impact strength, toughness etc, of the weld joint.

In this study, the same type joining of Aluminium alloys (AA6061 and AA6068) by friction stir welding process will be done and discussed in detail. The most significant parameters like thespeed of revolution of the pin, traverse speed, and geometry of the pin will be considered to study their effect on different mechanical properties such as tensile strength hardness test. The effect of process parameters on mechanical properties will be done by analysis of variance. Thus, the feasibility of the FSW process for similar joining of aluminum alloy will be assessed.

KEYWORDS: Friction-Stir Welding, CNC Horizontal Milling Machine, Different Materials, Tensile Strength, Brinell's Hardness Test \& Microstructure
\end{abstract}

Received: Mar 21, 2018; Accepted: Apr 11, 2018; Published: May 10, 2018; Paper Id.: IJMPERDJUN201851

\section{INTRODUCTION}

Friction stir welding is a strong state welding combination process development ensured by the Foundation of welding in 1991. The different types of aluminum alloys are accessible in the market, they are AA6061, AA5086, AA7075, and AA6068. The purpose of softening of the aluminum is by melting the workpiece to the temperature of 600degree-centigrade. If in this case the joining process should be done below the melting point of the base material.

It is very difficult to keen to measure the temperature during the weld zone of the plastic deformation. Metals or non-metals created by either by heating metals to the appropriate temperature or by with or without utilizing the pressure or use of pressure along with or without the utilizing of filler metal. Welding process is a stand out amongst the most utilized methods for joining pieces in the industry. The material temperature is raised to 
around $80 \%$ of the dissolving temperature.

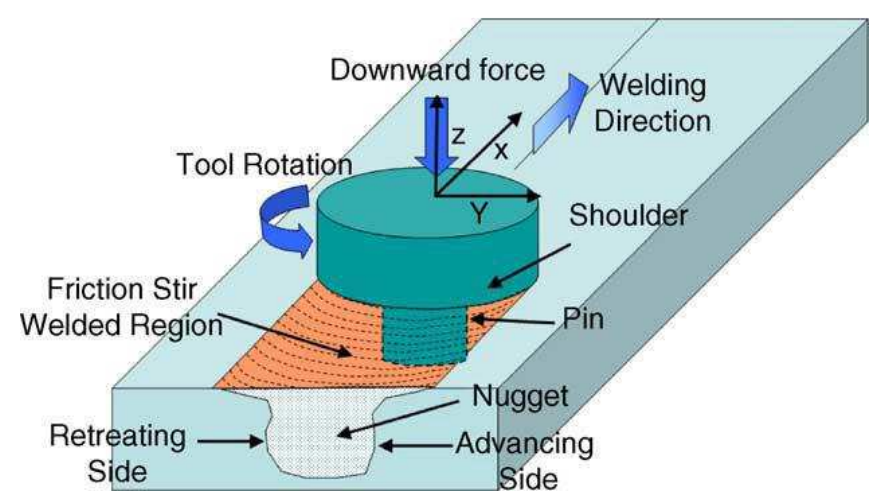

Figure 1.1: Schematic Diagram of FSW Process

\section{LITERATURE SURVEY}

As indicated by Raj Kumar. S [1], the best elasticity accomplished was $81.073 \mathrm{MPa}$ while welding at 900rpm with $25 \mathrm{~mm} / \mathrm{min}$ bolster by using the string device. The most shock hardness respected esteem accomplished was $267 \mathrm{HV}$ while welding at $1500 \mathrm{rpm}, 25 \mathrm{~mm} / \mathrm{min}$ encourage by utilizing the roundabout/round apparatus. The microstructure happens got and free from parts, splits, voids, non-metallic combinations and slags levels were discovered appealing. The utilization of string and decrease device profiles yields ideal gives better results over that of the round and square device profiles.

As per speech p [2], The rotational speed of $710 \mathrm{rpm}$, cross (or) navigates speed of $28 \mathrm{~mm} / \mathrm{min}$ and D/d extent of 3 , for round/roundabout device is accepted to be the best impact. Additionally, likewise, better mechanical properties were seen with $6 \mathrm{~mm}$ squared stick, the rotational speed of $1000 \mathrm{rpm}$ and cross (or)traverse speed of $40 \mathrm{~mm} / \mathrm{min}$. in like manner, the barrelshaped strung and squared stick profile are believed to be the best among other distinctive profiles that were considered.

As indicated by r. padmanabhan [3], The Tool pivot speed and welding velocity will influence the tensile quality of the joints. The tensile strength increments with increment in Tool pivot speed to an estimated value of $1050 \mathrm{rpm}$. Additionally, increment in Tool pivot speed would bring about decreases of tensile strength. Similarly the rigidity/tensile strength of joints increments with increment in Welding Speed up to $15 \mathrm{~mm} / \mathrm{min}$. Additionally increment in Welding Speed likewise brings about a diminishment in rigidity/tensile strength. Surface and contour plots uncover that the tensile strength would be exceptionally close to most extreme when the Tool pivot speed and Welding Speed are inside $1075 \mathrm{rpm}$ to $1125 \mathrm{rpm}$ and $13 \mathrm{~mm} / \mathrm{min}$ to $15 \mathrm{~mm} / \mathrm{min}$ separated.

As indicated by Thomas [4], centers around this investigation the generally new joining innovation, Friction stir welding (FSW). Friction stir welding can be utilized to join most aluminium combinations and surface oxide displays no trouble to the procedure. Based on this investigation, it was prescribed that number of lightweight materials reasonable for the car, rail, marine and aviation transportation businesses can be created (or) fabricated by FSW.

According to Mohd Anees Siddiqui [5], in the present examination to consider, a mimicked temperature of butt joint amid erosion blend welding of aluminium composite AA-6061 is by using Hyper Weld. The virtual examination is performed for seven assorted instruments rotational pieces from $600 \mathrm{revs} / \mathrm{min}$ to $900 \mathrm{revs} / \mathrm{min}$ with the progression of 50 $\mathrm{rev} / \mathrm{min}$ keeping the transverse speed of hardware nourish always at $2.5 \mathrm{~mm} / \mathrm{s}$. It is watched that the best temperature along the weld line of the welding plates is symmetrical and it increments with the development in rotational speed. 
It is also watched that the temperature at propelling side is continuously more that withdrawing side.

As per palanivel R [6] the joining of aluminum6351 and aluminum5083 utilizing the straight square pin profiled tool device at a welding speed/rate of $63 \mathrm{~mm} / \mathrm{min}$ demonstrated the best tensile properties.

\section{MATERIALS AND METHODS}

\subsection{Materials}

The Materials that have been utilized as a part of this work are Aluminum 6061 and Aluminum 6068 . The specified two materials are different aluminum alloy combinations. Aluminum is one of the delicate/soft materials when contrasted with different materials. The density of Aluminum 6061 is $2.7 \mathrm{GM} / \mathrm{cc}$, whereas the density of Aluminum 6068 is $2.8 \mathrm{GM} / \mathrm{cc}$. The material utilized for tool is high speed steel (H 13). It has its own points of interest, for example, high working hardness, high wear hardness, excellent strength, high maintenance of hardness and redness and some of the disadvantages when contrasted with other tool materials. At the point when contrasted with the other traditionalist materials utilized for tool, i.e. Tungsten Carbide or P20. H13 has an Ultimate Tensile Strength in the scope/range of 4700Mpa.

\subsection{Methods}

By and large, there has been an issue when welding distinctive aluminum combination materials as the properties of the materials separate/differ. Aluminum and Copper, generally, can't be welded using the customary ordinary combination blend welding process like Arc welding, Gas welding et cetera. It was shown that these materials could be profitably welded by using the Friction Stir Welding process. FSW is a solid state strong process

When appeared differently in relation to the next regular welding process that is a combination welding process. FSW has diverse preferences over other welding procedure like no hot part of the welded metals, no porosity, less leftover burden, protected and ecological cordial confined from others. After the materials were welded, distinctive tests like the Tensile quality test, Brinell's hardness test, and the microstructure tests were led/coordinated at the welded joint.

\section{EXPERIMENTAL SETUP}

The First Work piece is of Grade AA6061 and its composition is given underneath.

The Workpiece is having cross area of $100 * 50 * 5 \mathrm{~mm}$.

Table 1

\begin{tabular}{|c|c|c|c|c|c|c|c|c|c|}
\hline MG & Si & FE & CU & Ti & PB & ZN & MN & Ni & AL \\
\hline $0.8-1.5$ & 10 & 1 & 0.7 & 0.2 & 0.1 & 0.5 & 0.5 & 1.5 & 85.6 \\
\hline
\end{tabular}

The second Work piece is of Grade AA6068 and its composition is given underneath.

Workpiece is having cross area of $100 * 50 * 5 \mathrm{~mm}$.

Table 2

\begin{tabular}{|c|c|c|c|c|c|c|c|c|}
\hline MG & Bi & MN & FE & PB & CR & Ti & CU & AL \\
\hline 1.2 & 1.1 & 1.0 & 0.5 & 0.4 & 0.3 & 0.2 & 0.1 & 93.8 \\
\hline
\end{tabular}

Friction stir welding tool has been fabricated with high speed steel. (The composition shown below) 
Table 3

\begin{tabular}{|c|c|c|c|c|c|c|c|}
\hline Constituents & $\mathbf{C}$ & $\mathbf{M n}$ & $\mathbf{S i}$ & $\mathbf{S}$ & $\mathbf{P}$ & $\mathbf{C r}$ & $\mathbf{n i}$ \\
\hline$\%$ & 0.4 & 1.5 & 1.5 & 0.05 & 0.05 & 18 & 5.0 \\
\hline
\end{tabular}

The experimentation has been carried out by using properly clamping fixtures that allows fixing the two sheets. The dimensions are $(100 \mathrm{~mm} * 50 \mathrm{~mm} * 5 \mathrm{~mm})$ to be welded butt joint by using CNC vertical milling machine.

\section{METHODOLOGY}

In the experimentation, we are using three types of tool profiles, namely 1) cylindrical too 2) square tool 3) taper tool

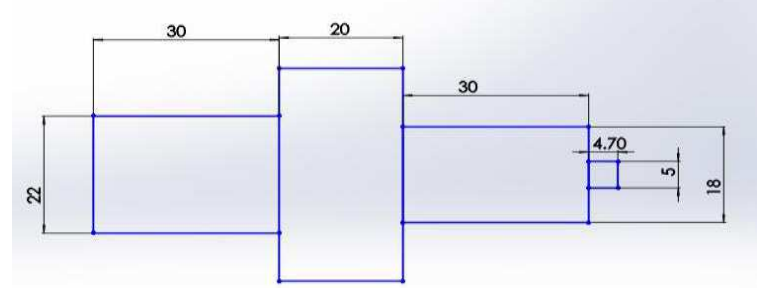

Figure 5.1: Dimensions of Tool Profile

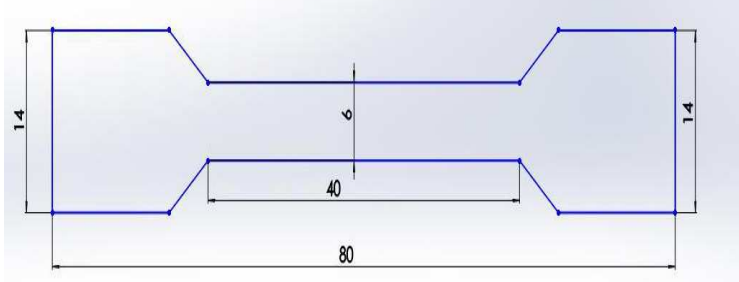

Figure 5.2: Tensile Test Specimen Standards

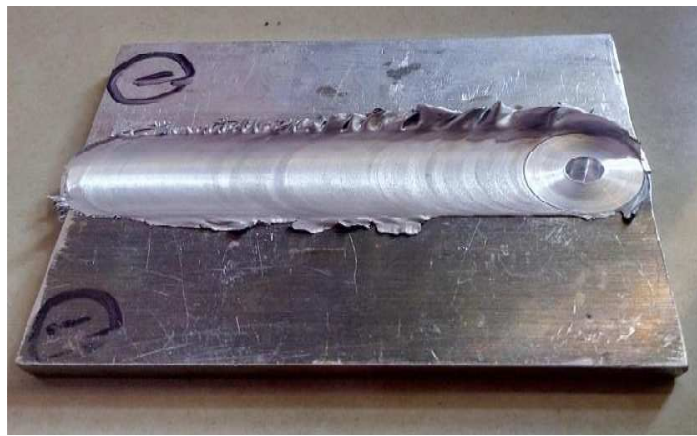

Figure 5.3: Welded by using Cylindrical Tool

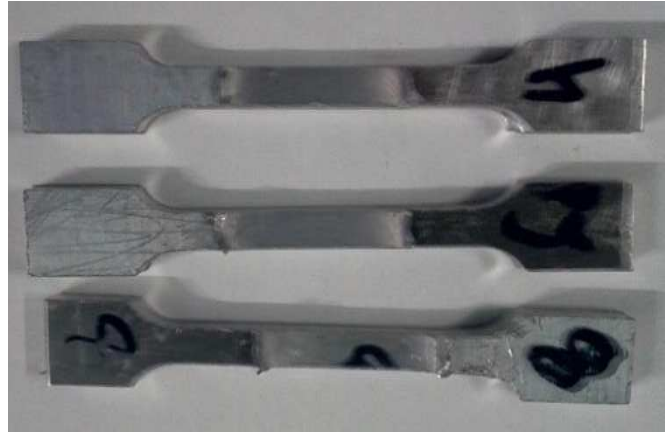

Figure 5.4: Tensile Test Specimen

Figure 5.3: Shows the welded plates is welded utilizing the cylindrical/round pin tool, rotating at 450rpm with $25 \mathrm{~mm} / \mathrm{min}$ feed rate and tilt edge angle of $2^{\circ}$.

Figure 5.4: The tensile test specimens are demonstrated. The tensile test specimens are cut according to the ASTM standards. The above specimens are for the testing of the welding made by the square tool profile. 


\subsection{Micro Structure}

A deliberately prepared example, specimens and magnification are required for microscopic examination. Appropriate arrangement of the example and the material's surface requires that an inflexible well-ordered process is taken after. The initial step is precisely choosing a little example of the material to experience microstructure investigation with thought given to the area and introducting. It is trailed by separating, mounting, crushing, cleaning and drawing to uncover precise microstructure and pieces. The etchant utilized was $2 \% \mathrm{HF}$ and $\mathrm{K} 2 \mathrm{CrO} 7+\mathrm{HNO} 3$. An amplification of 100X, 450X, $600 \mathrm{X}$ was utilized for point by point survey of tests utilizing a progress rearranged magnifying lens with picture analyzer.

\subsection{Brinell's Hardness Test}

The Brinell's hardness test system as used to decide how much hardness of that material have, most conventionally it is used to test materials that have a structure that is unreasonably coarse or that have a surface that is too harsh to be in any capacity tried using another test strategy, for eg; castings and forgings. Brinell's trying to frequently use a high test to stack (3000kgf) and a $10 \mathrm{~mm}$ distance across of the indenture with the objective that the consequent coming about space midpoints out the most surfaces and sub-surface inconsistence.

In this experimentation, we are using an aluminium alloys (AA6061 and AA6068) while applying a constant load of 500kgf force (F) due to because of non-ferrous materials and the diameter of the indenture is $10 \mathrm{~mm}$ (D) we have applied a load of $20 \mathrm{sec}$ of time of each experiment and after using the designed Brinell's microscope. we are calculating the at least two diameters usually at right angles to each other and these results are average and then calculated as indentation diameter (d), after that by using the Brinell's hardness number we are calculating the hardness valve for each experimentation.

\subsection{Thermal Analysis}

So as to find the temperatures at various rpms. We are doing the thermal analysis on hyper works software. When the tool is turning/rotating at $450 \mathrm{rpm}$ and traverse speed of $25 \mathrm{~mm} / \mathrm{min}$ by utilizing cylindrical tool device.

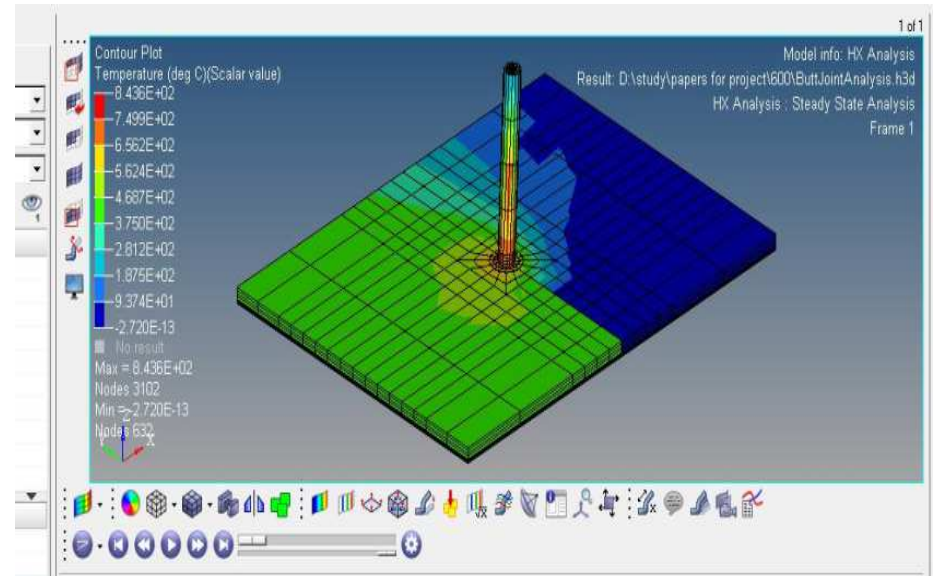

Figure 5.3.1: Isometric Perspective of Finite Limited Component Show for FSW process with Appropriated Stacked Reproduction after Effects of Temperature Conveyance along the Weld Line Showed up in the principle Realistic Zone

When the tool device is rotating at $560 \mathrm{rpm}$ and traverse speed of $25 \mathrm{~mm} / \mathrm{min}$ by utilizing round/cylindrical tool device. 


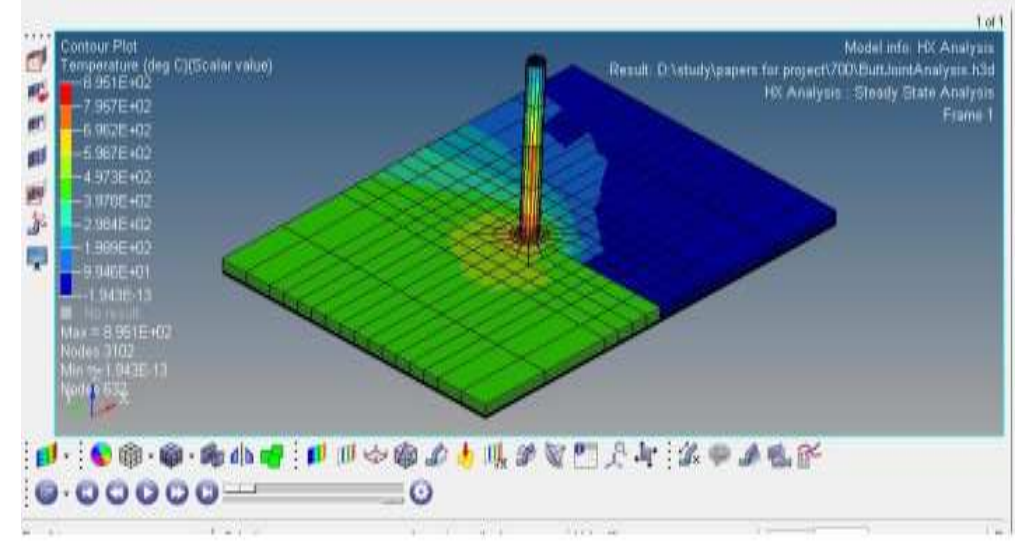

Figure 5.3.2: Isometric Perspective of Finite Limited Component Show for FSW Process with Appropriated Stacked Reproduction after Effects of Temperature Conveyance along the Weld Line Showed up in the Principle Realistic Zone

\section{RESULTS AND DISCUSSIONS}

\subsection{Thermal Analysis Result}

In this experimentation we find the temperatures by using hyper work's software, in this experimentation, we are going to calculate the temperature by using a cylindrical tool at 2 different rpm's

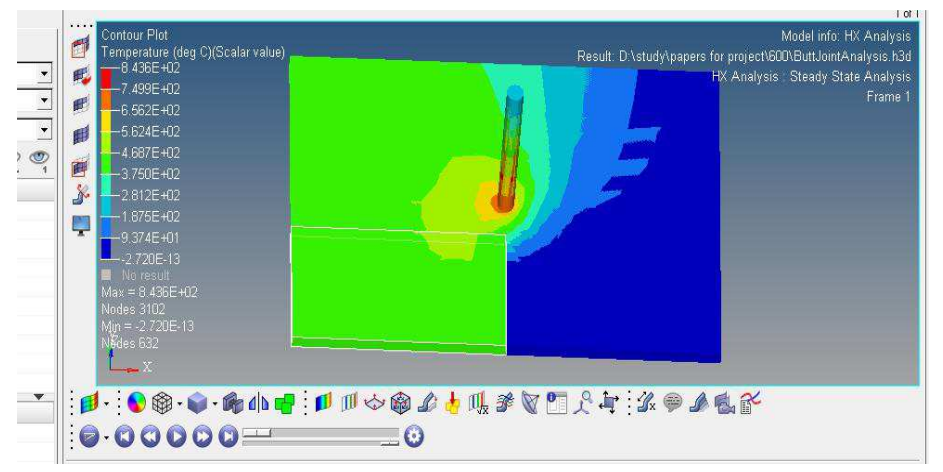

Figure 6.1.1: Temperatures by using the Cylindrical Tool at $450 \mathrm{rpm}$

In the above figure it clearly shows that when the tool is rotating at $450 \mathrm{rpm}$ and feed rate of $25 \mathrm{~mm} / \mathrm{min}$ by using a cylindrical tool. we got min temperature at room temperature at $27^{\circ} \mathrm{c}$ and max temperature at $700^{\circ} \mathrm{c}$.

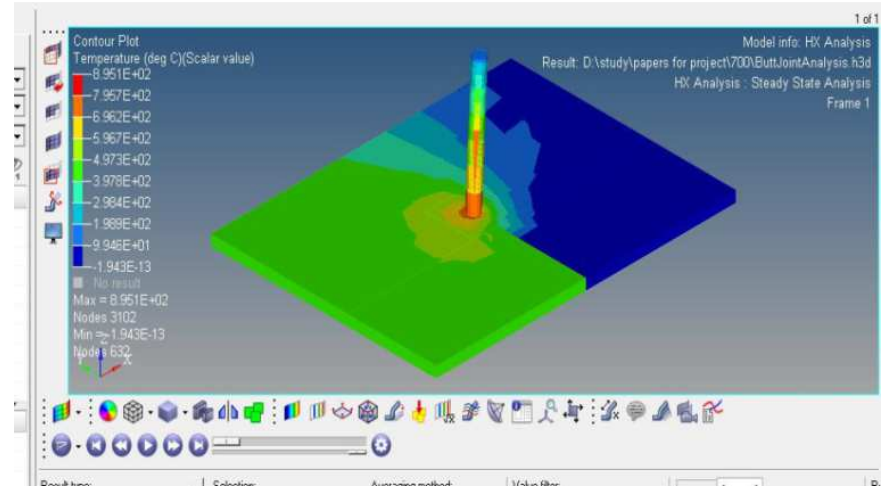

Figure 6.1.2: Temperatures by using the Cylindrical Tool at $560 \mathrm{rpm}$ 
In the above figure it clearly shows that when the tool is rotating at $560 \mathrm{rpm}$ and feed rate of $25 \mathrm{~mm} / \mathrm{min}$ by using a cylindrical tool. we got min temperature at room temperature at $27^{\circ} \mathrm{c}$ and max temperature at $734^{\circ} \mathrm{c}$.

\subsection{Tensile Test Result}

Table 6.2.1: Tensile Test Results

\begin{tabular}{|c|c|c|c|c|c|c|c|c|}
\hline Sample & RPM & $\begin{array}{c}\text { FEED } \\
\mathbf{m m} / \mathbf{m i n}\end{array}$ & $\begin{array}{c}\text { Load } \\
\text { at Yield } \\
(\mathbf{k n})\end{array}$ & $\begin{array}{c}\text { Yield } \\
\text { Stress } \\
\left(\mathbf{N} / \mathbf{m m}^{\mathbf{2}}\right)\end{array}$ & $\begin{array}{c}\text { Load } \\
\text { at peak } \\
(\mathbf{K N})\end{array}$ & $\begin{array}{c}\text { Tensile } \\
\text { strength } \\
\left(\mathbf{N} / \mathbf{m m}^{\mathbf{2}}\right)\end{array}$ & $\begin{array}{c}\text { elongation } \\
\text { in } \\
(\boldsymbol{\%})\end{array}$ & $\begin{array}{c}\text { Tool } \\
(\mathbf{P i n}) \\
\mathbf{p r o f i l e}\end{array}$ \\
\hline 1 & 450 & 25 & 5.06 & 139.637 & 6.170 & 170.269 & 22.52 & cylinder \\
\hline 2 & 450 & 25 & 4.01 & 107.265 & 5.630 & 150.598 & 14.88 & square \\
\hline 3 & 560 & 25 & 4.8 & 131.144 & 5.760 & 157.373 & 14.92 & cylinder \\
\hline 4 & 560 & 25 & 5.08 & 151.426 & 6.270 & 186.898 & 17.68 & square \\
\hline 5 & 710 & 25 & 4.56 & 122.348 & 5.470 & 146.764 & 16.44 & cylinder \\
\hline 6 & 710 & 25 & 4.41 & 119.764 & 6.300 & 171.092 & 15.56 & square \\
\hline 7 & 900 & 25 & 4.75 & 126.822 & 6.210 & 165.803 & 14.04 & cylinder \\
\hline 8 & 900 & 25 & 4.43 & 113.79 & 5.350 & 137.422 & 16.04 & square \\
\hline 9 & 450 & 25 & 4.3 & 109.555 & 5.520 & 140.638 & 10.12 & Taper \\
\hline 10 & 560 & 25 & 5.47 & 149.233 & 6.540 & 178.425 & 16.24 & Taper \\
\hline 11 & 710 & 25 & 4.55 & 122.115 & 5.760 & 154.589 & 17.12 & Taper \\
\hline 12 & 900 & 25 & 4.63 & 127.343 & 5.950 & 163.649 & 17.04 & Taper \\
\hline 13 & 1400 & 25 & 3.52 & 95.238 & 4.460 & 120.671 & 11.56 & Taper \\
\hline 14 & 1120 & 25 & 5.04 & 141.203 & 6.360 & 178.184 & 12.08 & Taper \\
\hline
\end{tabular}

In the Table the most tensile strength of $186.898 \mathrm{~N} / \mathrm{mm}^{2}$ watched while working at $560 \mathrm{rpm}$ and nourish of $25 \mathrm{~mm} / \mathrm{min}$ with the square instrument profile. Under comparable working conditions, the second most elevated quality of $178.425 \mathrm{~N} / \mathrm{mm}^{2}$ was accomplished with the decrease apparatus. The third most astounding quality of $170.269 \mathrm{n} / \mathrm{mm}^{2} \mathrm{was}$ accomplished

With the round and hollow instrument while working at $450 \mathrm{rpm}$. The least quality accompanied the decrease apparatus profile and it was $120.671 \mathrm{~N} / \mathrm{mm}^{2}$ while working at $1400 \mathrm{rpm}$ and sustain the rate of $25 \mathrm{~mm} / \mathrm{min}$. By and large, the outcomes acquired for the elasticity were attractive.

\subsection{Brinell's Hardness Test Result}

The Brinell's hardness test was performed on the different regions on the welded joints. Three regions of spaces on the joints were taken, i.e., the first region space on the AA6061 plate, the second region space on the AA6068 plate, the last one is on the weld locale. Midpoints of all the three positions were figured and the hardness numbers were noted down.

Table 6.3.1: Brinell's Hardness Test Results

\begin{tabular}{|c|c|c|l|c|c|c|c|}
\hline $\begin{array}{c}\text { Sample } \\
\text { No }\end{array}$ & RPM & $\begin{array}{c}\text { Feed } \\
\text { mm/min }\end{array}$ & $\begin{array}{c}\text { Tool } \\
\text { Profile }\end{array}$ & $\begin{array}{c}\text { Indentation } \\
\text { 1(AA6061) }\end{array}$ & $\begin{array}{c}\text { Indentation } \\
\text { 2(AA6068) }\end{array}$ & $\begin{array}{c}\text { Indentation } \\
\text { 3weld region }\end{array}$ & Average \\
\hline 1 & 450 & 25 & Cylinder & 47.47 & 56.82 & 32.75 & 45.68 \\
\hline 2 & 450 & 25 & Square & 42.43 & 42.43 & 29.75 & 38.20 \\
\hline 3 & 560 & 25 & Cylinder & 50.32 & 53.43 & 32.75 & 45.5 \\
\hline 4 & 560 & 25 & Square & 31.20 & 40.19 & 32.75 & 34.71 \\
\hline 5 & 710 & 25 & Cylinder & 47.47 & 56.82 & 38.12 & 47.47 \\
\hline 6 & 710 & 25 & Square & 32.75 & 34.42 & 34.42 & 33.86 \\
\hline 7 & 900 & 25 & Cylinder & 42.43 & 34.42 & 32.75 & 36.53 \\
\hline 8 & 900 & 25 & Square & 28.39 & 36.20 & 20.94 & 28.51 \\
\hline 9 & 450 & 25 & Taper & 42.43 & 31.20 & 29.75 & 34.46 \\
\hline 10 & 560 & 25 & Taper & 28.39 & 38.12 & 36.20 & 34.23 \\
\hline
\end{tabular}




\begin{tabular}{|c|c|c|c|c|c|c|c|}
\hline \multicolumn{7}{|c|}{ Table 6.3.1: Contd., } \\
\hline 11 & 710 & 25 & Taper & 36.20 & 36.20 & 38.12 & 36.84 \\
\hline 12 & 900 & 25 & Taper & 32.75 & 50.32 & 34.42 & 39.16 \\
\hline 13 & 1400 & 25 & Taper & 28.39 & 42.43 & 44.85 & 38.55 \\
\hline 14 & 1120 & 25 & Taper & 34.42 & 42.43 & 40.19 & 39.01 \\
\hline
\end{tabular}

The outcomes are classified as appeared in the above Table. The most elevated hardness number is accomplished for the roundabout/round instrument, which is $47.47 \mathrm{HV}$. The most minimal hardness number was accomplished for the square apparatus which is $28.51 \mathrm{HV}$, and the hardness number accomplished for the decrease instrument of most elevated is $39.16 \mathrm{HV}$. This demonstrates it isn't vital that a weld joint having the most noteworthy elasticity ought to likewise have the most elevated hardness number. The second most astounding hardness esteem was accomplished when decrease apparatus was utilized. By and large, the outcomes got from the Brinell's hardness were palatable.

\subsection{Microstructure Result}

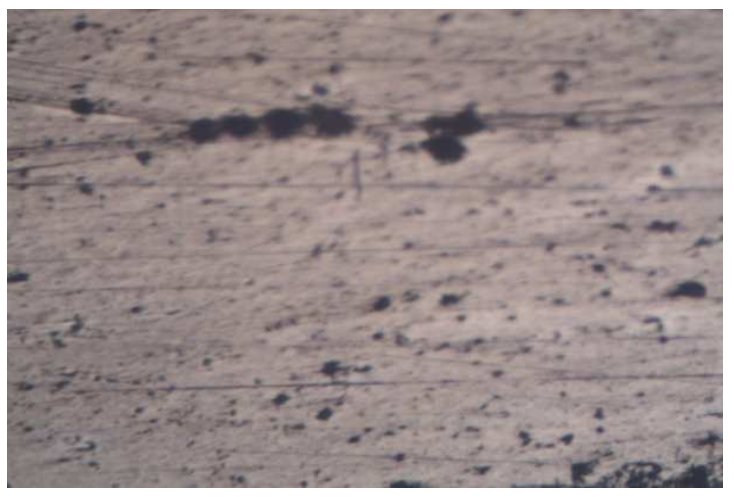

Figure 6.4.1: Microstructure for Cylindrical Tool

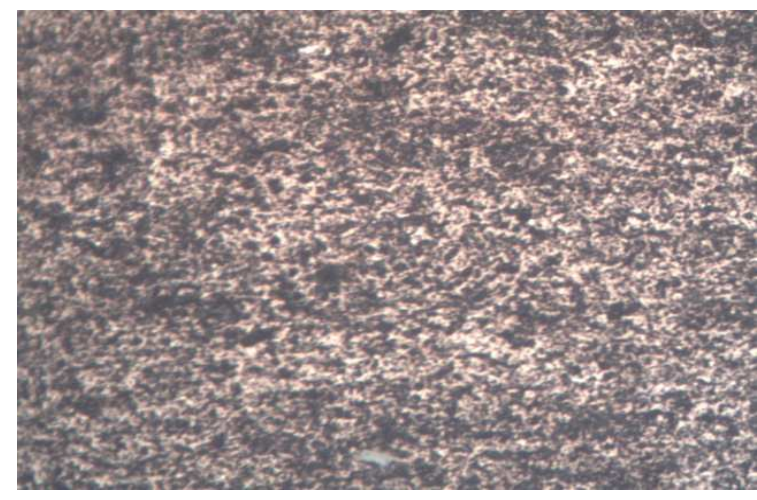

Figure 6.4.2: Microstructure for Square Tool

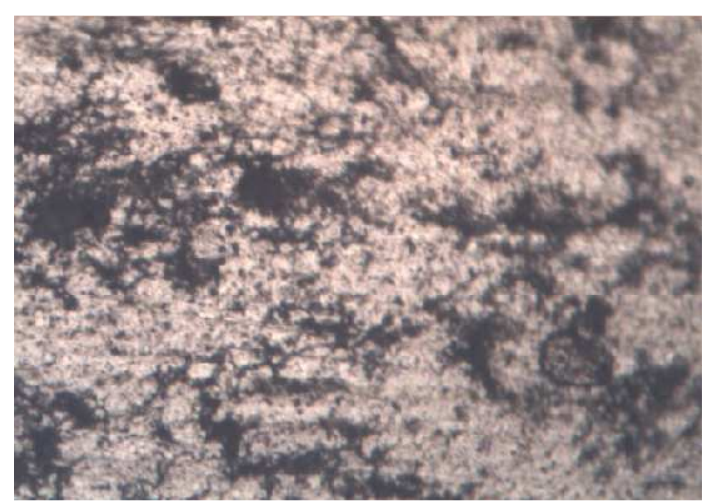

Figure 6.4.3: Microstructure for Taper Tool

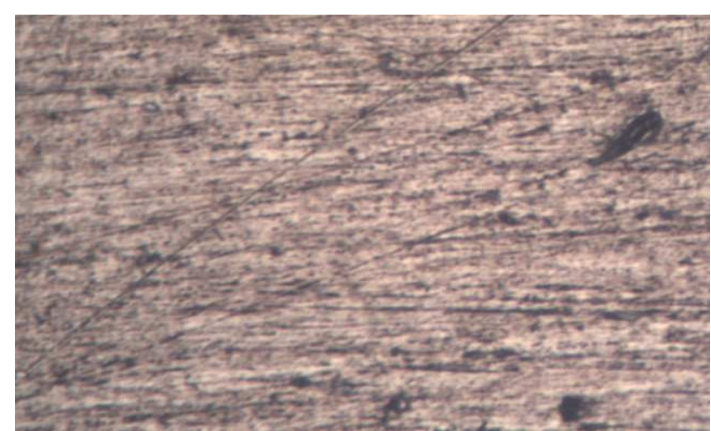

Figure 6.4.5: Microstructure for Taper Tool

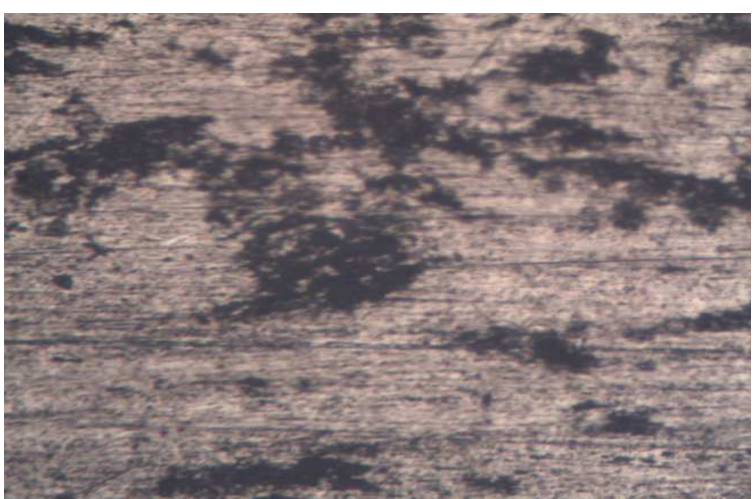

Figure 6.4.4: Microstructure for Cylindrical Tool

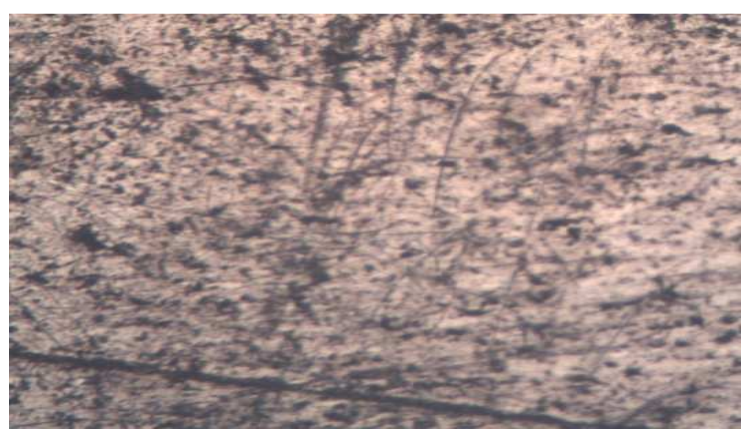

Figure 6.4.6: microstructure for Square Tool 
The above figures the microstructure of the welded joint, when welded at 450, 560, 710, $1400 \mathrm{rpm}$ with sustained $25 \mathrm{~mm} / \mathrm{min}$ using the square, cylindrical, taper apparatus profile. The underlying advance is intentionally picking a little example of the material to experience/encounter the microstructure examination with thought given to the zone and introduction. This movement is trailed by segmenting mounting, granulating, cleaning and carving. The dark/silverish territories are cut aluminum rich while the brilliant dark black dots being copper-rich areas. The joint interfaces are portrayed by blended layers of aluminum and copper as clear in the microstructures coming about because of the warmth contribution to the welds by the infiltrating of the instrument amid the FSW procedure.

\section{CONCLUSIONS}

The best Tensile strength achieved was $186.898 \mathrm{~N} / \mathrm{mm}^{2}$ welding at $560 \mathrm{rpm}$ with $25 \mathrm{~mm} / \mathrm{min}$ encourage using the square tool. The most outrageous hardness esteem achieved was 47.47BHV while welding at $710 \mathrm{rpm}, 25 \mathrm{~mm} / \mathrm{min}$ nourish using the round tool device. The microstructure comes about got were discovered free from breaks, voids and non-metallic consolidations and slags levels were discovered attractive. It can along these lines be contemplated that usage of the tool and decrease device profiles yield gives best result comes about finished that of round and square device profiles.

\section{REFERENCES}

1. Rajakumar, S., C. Muralidharan, and V. Balasubramanian. "Predicting tensile strength, hardness and corrosion rate of friction stir welded AA6061-T6 aluminium alloy joints." Materials \& Design 32.5 (2011): 2878-2890.

2. Sadeesh, P., et al. "Studies on friction stir welding of AA 2024 and AA 6061 dissimilar metals." Procedia Engineering 75 (2014): 145-149.

3. Padmanaban, R., V. Balusamy, and K. N. Nouranga. "Effect of Process Parameters on the Tensile Strength of Friction Stir WeldedDissimilar Aluminum Joints." journal of Engineering Science and Technology 11.1 (2016): 12.

4. Thomas, Wayne M. "Friction stir welding and related friction process characteristics." Proc. 7th Int. Conf. on 'Joints in aluminium-INALCO. Vol. 98. 1999.

5. Siddiqui, Mohd Anees, S. A. H. Jafri, and Shahnawaz Alam. "Validation of Maximum Temperature during Friction Stir Welding of Butt Joint of Aluminium Alloy by using HyperWorks." International Journal of Engineering Research and Technology 4.04 (2015)..

6. Cárach, Ján, et al. "Hydroabrasive disintegration of rotating Monel K-500 workpiece." The International Journal of Advanced Manufacturing Technology 96.1-4 (2018): 981-1001.

7. Zna, N. A. T. E. Z. N. E., ILNOSTI TORNIH Pomi, and N. Zvarov. "The tensile behavior of friction-stir-welded dissimilar aluminum alloys." Materiali in tehnologije 45.6 (2011): 623-626.

8. Kumbhar, N. T., and K. Bhanumurthy. "Friction stir welding of Al 6061 alloy." Asian J. Exp. Sci 22.2 (2008): 63-74.

9. Sattari, S., H. Bisadi, and M. Sajed. "Mechanical properties and temperature distributions of thin friction stir welded sheets of AA5083." International Journal of Mechanics and Applications 2.1 (2012): 1-6.

10. Babu, N., N. Karunakaran, and V. Balasubramanian. "A study to estimate the tensile strength of friction stir welded AA 5059 aluminium alloy joints." The International Journal of Advanced Manufacturing Technology 93.1-4 (2017): 1-9.

11. Kumar, I. Ajit, and M. V. Mallikarjuna. "Thermal Analysis of Friction Stir Welding."

12. Khourshid, A. M., and I. Sabry. "Analysis and design of Friction stir welding." Int. J. Mech. Eng. \& Rob. Res (2013): 22780149. 
